\title{
The Research on the Project Teaching Design of "Building Environment" in University Building Environment and Energy Application Engineering Specialty
}

\author{
Xuejin Wang ${ }^{1, \text { a }}$, Jing Hong ${ }^{2, \text { a }}$, Zhihong Zhang ${ }^{3, \text { a }}$,Yujin zhang ${ }^{4, \text { a }}$
}

Hebei Institute of Architecture and Civil Engineering Department of Energy and Environmental

Engineering Hebei Zhangjiakou, China

wangxuejin@126.com

Keywords: project teaching design; building environment; building environment and energy engineering; project selection; project oriented teaching evaluation

\begin{abstract}
The thesis "building environment science" course as an example, in the building environment and energy engineering professional training under the guidance of the target, of the course of project teaching design, and selected according to the characteristics of the course in the project, the teaching project design, project teaching evaluation of three aspects, and puts forward the specific implementation measures. the project teaching design of "Building environment" in University building environment and energy application engineering specialty will have a great promotion in improving the quality of teaching.
\end{abstract}

\section{Introduction}

The building environment and energy engineering major task is to building as the main object, and make full use of natural energy based by artificial environment and energy using engineering techniques to create human life and work for the comfortable, healthy, environmental protection and energy saving, building environment and meet the requirement of production and scientific experiments of the process environment, and special application in the field of artificial environment. Along with the development of social economy and the progress of science and technology, human living and production of the built environment requirements gradually increase, the rapid growth of building energy consumption, the talents of building environment and energy engineering professional training put forward higher requirements.

Building environment is one of the four basic courses of building environment and energy engineering specialty. It is the core basic course of building environment and equipment engineering specialty. The built environment "contains the contents of the building, heat, sound, light, material, physical and psychological disciplines, is a interdisciplinary borderline subject, because of the course covers a wide range, large amount of information and knowledge of teaching materials system, and many content involves the front field of science and technology, making the teaching and it is difficult to grasp the core knowledge, if you want to in the limited class time, so as to enable students to acquire knowledge, but also to cultivate the students to take the initiative to acquire knowledge of the teaching objectives, no easy task. ${ }^{[1]}$

Project teaching to the project as the main line throughout the whole teaching process can the knowledge of the contents of the different chapters, different disciplines and different curriculum effectively fusion together, can also let the students a detailed analysis of the project under the guidance of teachers, through the students involved in the project autonomous learning, we use the theory of knowledge, the completion of the project, to realize the theory, practice integration teaching, teachers to students completed project quality to evaluate the learning effect of students

According to the built environment of professional training objectives, the built environment "the characteristics of curriculum characteristics and project type teaching method, it is not difficult to see that, implementation of project teaching not only to students acquire knowledge and training the ability of students to take the initiative to acquire knowledge is a can achieve the goal of teaching the course of effective teaching mode, is one of the effective ways for the construction of ring the application type undergraduate engineering innovation personnel training. The project 
teaching design is the skeleton of the course project teaching, which is the key to the successful implementation of the project teaching.

Project oriented teaching design mainly includes project selection, project teaching and project teaching evaluation.

\section{Project selection}

Project is the core of project oriented teaching activities. How to find the right project is one of the most difficult tasks in the project teaching. Project at least need to meet the following requirements: A, the project must be challenging; second, the project has successfully completed the possibility of; project must be common, there are enough literature accessible; project that the theory of application; fifth, to meet the regulations and safety standards; six, if enterprises to participate in the project, not related to enterprise's private information. In addition, the project is only to achieve the level of close to the reality of the value, the time required to complete the project must be limited in the course of the project. ${ }^{[2][3][4][5]}$

\subsection{Project direction}

College building environment and energy application engineering professional training objectives, is the "building environment," the project of the project selection of teaching project, you can choose a different direction of the project. A, career direction, its purpose is in both theory and practice to build bridges, to meet the needs of industry and society and the labour market; second, the criticism of scientific direction, in order to cultivate critical thinking, emphasizing the needs of multidisciplinary or interdisciplinary research and education; third, the direction of education, the use of the problem as the center and active learning methods to train students to promote their overall development.

\subsection{Project type}

According to the students' own personality advantages and career planning, you can also choose three different types of projects: first, the task of the project (project task). The project is given by the instructor, and the students are in accordance with the requirements of the teachers. This kind of project is to provide students with less learning motivation and skills development, and is also more commonly used in the project selection method; two is the subject project (project discipline). The subject areas of guidance teachers definition of project, formulated to be used by the various methods, but project specific and concrete methods of the design by the students to determine; third, projects that project (problem project). That the project and the use of the method is completely independent choice by the students.

\section{Project oriented teaching design scheme}

In the first Introduction chapter of teaching, let students access to information, set the project for looking building in the course of the evolution of the typical architectural form, each of the studies a traditional architectural forms, through the research project learning traditional building green ecological ideas, and discussed its started in adapting to the environment, so as to stimulate students of building environment of interest in learning.

In Chapter II building environment of teaching, teaching effect of thermal and humidity environment of physical factors and calculation design parameters linked to set up a project of ring professional courses in the air conditioner outdoor building; can also be outside the building environment and building energy consumption impacts linked to set up a project; can according to students' different source areas, organize the differences in different regions outside the building environment analysis or outdoor meteorological parameters measured and calculated to set up a project, such as test and analysis of city heat island effect; combined with the building environment 
outdoor meteorological parameters and architectural climatic zoning, to examine in hot summer and cold winter area winter heating is necessary to set up a project.

In chapter three thermal and humidity environment of teaching can be set for "building heat and moisture environment influencing factors of the project. In the project arrangement can be on with a form of construction for students to change building orientation, enclosure structure and change in parameters such as heat source method. Through the analysis of the change of the subject, the influence of the factors on the change of the building load is found. Building heat and moisture environment in various forms of heat and mass transfer and its calculation method and need to let the students will pass thermotics course in application of theoretical knowledge, the principle of forming and building heat and moisture loads and subsequent HVAC curriculum in cooling and heating load calculation is also the corresponding, load calculation method for harmonic response method and the cooling load coefficient method, to solve complex calculation computer program or application of common calculation software further for a given map building buildings in summer cooling load calculation to set the project, can let the students master the heat and moisture environment load calculation principle and method, but also for subsequent courses design lay a good load calculation.

In the fourth chapter of the reaction to the hot and humid environment, the students of a specific indoor air conditioning of the environmental parameters of the test and the questionnaire, such as temperature, air humidity, wind speed, etc.. Through appropriate parameter control, with thermal comfort of the instrument control parameters affect the change of the parameters, and then let the students according to the knowledge of environmental science, combined with the physiological and psychological foundation, designed questionnaire and the test environment evaluation, before finally by the integrated use of the related courses, such as fluid mechanics, engineering thermodynamics and higher mathematics knowledge analysis calculation of test results for corresponding environmental thermal comfort index, such as PMV, PPD indicators, finally according to the results to evaluate human indoor comfort. By comparing the differences between the questionnaire survey and the actual measurement results, the method of combining the subjective and objective method to evaluate the indoor environment quality is analyzed. The implementation of the project can enable students to master the different factors of hot and humid environment, and grasp the factors affecting human body comfort, also can acquire the body of thermal wet comfort of the evaluation method and index calculation, and can basically covers the main content of the fourth chapter.

In chapter five of indoor air quality in teaching, such as in studying the related factors of indoor air quality, different groups to different functions of the building were detected, such as setting the specific office location, family's living environment or in public places (shopping malls, hospitals, etc.). The practice link in classrooms, faculty offices, student dormitories, canteens and other buildings as the object of indoor environment analysis and evaluation, the evaluation can be combined with a questionnaire survey or actual measurement means. The questionnaire survey in addition to the basic understanding of the building, and chapter three hot and humid environment and Chapter IV of hot and humid environment response together, even behind the seventh chapter of the architectural acoustic environment, and the eighth chapter building light environment contact together, understand teachers and students on indoor thermal and humidity environment, indoor air quality, sound environment and light environment satisfaction and attention degree. Measured by the instrument on the impact of indoor environmental quality specific parameters (including temperature, relative humidity, wind speed, noise, etc.) were measured in the use of the building time, and real-time monitoring the outdoor one day the temperature, humidity and wind speed. Preparatory work includes: according to the nature of the building design of the content of the questionnaire survey, design and testing program; familiar with the use of related instruments, etc.. The specific content of the questionnaire included architectural characteristics, including building categories, as well as the decoration, orientation, size, number of layers and forms; investigation personnel, containing identity, age, gender, smoking; indoor temperature and humidity, including whether there are fans and air-conditioning, indoor thermal and humid feeling, satisfaction, 
personnel clothing status; indoor air quality, ventilation, whether the smell, on air quality satisfaction; noise and illumination, noise and illumination, the acoustic environment and light environment satisfaction. Students according to the construction quality and personnel differences, design content will be different. Detection scheme according to the nature and size of the building is different, such as the program of the classroom and cafeteria certainly different.

In chapter six indoor air environment to create the basic theory teaching, teaching airflow in air-conditioned room, the ventilation and air conditioning design of purification and air distribution design combined to set up a project, can according to the different outlet types as the theme group start research projects, master the related factors of airflow in air-conditioned room, and have learned the first courses of "fluid mechanics" course give, return to the (row) air flow motion laws, so as to reflect the basic function and practical application.

Of course, the development of the project is not necessarily an observation or experiment, but also allows students to do a literature review of the relevant content. Through a large number of reading at home and abroad the latest literature, the current research of the related projects, the existing problems, solutions, the development direction of the one cited. Students through the implementation of the project, you can understand the current problems of the subject. In addition, the implementation of the project can provide ideas and materials for teachers in the teaching process to achieve better teaching effect.

Project teaching not only to focus on project teaching and together to complete the implementation of the project, to play the subjective initiative of students, but also should pay attention to during the later period project report writing and answering other links, cultivate students innovation spirit. In the early stage of the project, the teacher helps students to complete the project selection and analysis. With the implementation of the project, the students gradually become the center of the project.

In the course of the whole process, the students will encounter many of the classroom did not speak, or they have not mastered the knowledge, which requires students to carry out autonomous learning, autonomous. Teachers should regularly check the progress of the project, and guide students to meet the problems in time. In the course of the implementation of the project, students generally require students to apply the knowledge and skills of two or more than two courses, and sometimes even to cross disciplinary. For the knowledge and skills, students through participation in the project of active learning can consolidate the original knowledge, cultivating innovative ability, also can be the contents of the different chapters, different disciplines of knowledge and even different curriculum effectively fusion together.

\section{Project oriented teaching evaluation}

What students learn, and how to learn a large extent depend on what they think they will be in the way they will be evaluated. This means that it is very important to determine the scientific and effective teaching method for the students' learning effect and ability. However, choose what kind of project teaching evaluation method is a very difficult task and must be considered by who to evaluate, the basis and standard of the evaluation is what, and how to prove that the students master the knowledge and skills. The teaching evaluation of the project is mainly based on the self evaluation, the evaluation of the members of the project team, the guidance of the teacher evaluation, and the evaluation of the combination of various evaluation. ${ }^{[6]}$

Self evaluation method is not objective of the evaluation of the defect, not recommended.

Project team member mutual evaluation method can improve the enthusiasm of students to participate in the project, the individual efforts of team members can be effectively screened out. Team members understand each other's work in the project, and can determine the contribution of each team member to the project through the project team members. But members of the project group mutual evaluation also has the flaw, namely the whole project team achievement can not and team members completed, and the achievements of the whole project team directly determine project members of the evaluation results. 
Instructor evaluation can be inspected the project process, by marking investigation report, questioning and by the members of the project evaluation reply link test project, give the corresponding points and evaluation results corresponding to. For example, "building heat and moisture environment factors affect the project and on a specific indoor air-conditioning environment parameters of test and questionnaire survey project, according to calculation and measurement data analysis and questionnaire survey results evaluation of the measured object summer one day of indoor environment status and effect of present situation of environmental factors and improve the indoor environment measures analysis. Finally, report submitted to the indoor environment status investigation and assessment, impact environment factors and improving indoor environmental measures analysis, process and final project report guidance teachers can guide evaluation.

In addition, teachers can also through project evaluation and the part of the respondent, more in-depth courses unresolved questions, leads to project matters, such as specific methods to improve the construction of indoor air environment problems, to be further introduces the "ventilation engineering" and "air conditioning engineering; environmental information content to improve, in" building automation "course such as introduction; other environmental factors, such as sound, light, electromagnetic and architectural space layout, but also in related professional elective courses in further introduction. Such not only can lead to subsequent courses need to solve the knowledge, the students the subsequent courses is more targeted, but also makes the students have strong further courses learning interest and motivation. Because of the lack of guidance to the students' knowledge and skills to master the degree of understanding, leading to the guidance of teachers' evaluation method is often subjective strong. And, this evaluation method mainly adopts the traditional answer the test and evaluation report, not effectively assess students through the project of communication, interpersonal and teamwork skill mastery.

In the actual operation process, can use a variety of evaluation methods, which is to guide the evaluation of teacher evaluation and project team members to evaluate the combination of each other. First by the teacher to the team achievements evaluation, and then according to the contribution of the project team members, the team performance score assigned to each team member.

\section{References}

[1] Zhu yin xin. Building environment. Third Edition. Beijing: China Building Industry Press, 2010.

[2] Alan J. Dutson, Robert H. Todd, Spencer P. Magleby, etal. A review of literature on teaching engineering design through project-oriented capstone eourses [J]. Journal of Engineering Education, 1997, 86(1): 17-28.

[3] Debelak, K. A . , J. A. Roth. Chemical process design : an integrated teaching approach[J]. Chemical Engineering Education, 1982, 16(2): 72-75.

[4] Jakubowski, G. S . , R. Sechler. SAE student design com-petitions as captone courses[C]. Proceedings, Advances in Capstone Education Conference, Brigham Young Universtiy, 1994.

[5] Smith, M. J. Use of a process simulation computer program in an industry project capstone design course[C]. Proceedings, 1991 ASEE Annual Conference, 1991

[6] Lejk, M. , Wyvill, M, Farrow, S. A survey of methods of deriving individual grades from group assessments[J]. As-sessment \& Evaluation in Higher Education. 1996, 21(3): 267-280. 